\title{
El imaginario de la crisis: caricatura económica en Colombia en la época de la Gran Depresión
}

The Imaginary of the Crisis: Economic Cartoon in Colombia in times of the Great Depression

\author{
Marta Juanita Villaveces Niño \\ Profesora asociada Facultad de Economía, Universidad del Rosario. \\ http://orcid.org/0000-0001-6185-4470 \\ marta.villaveces@urosario.edu.co \\ Paul Rodríguez Lesmes \\ PhD (student) in Economics, University College of London \\ http://orcid.org/ 0000-0003-1058-3062. \\ p.lesmes.11@ucl.ac.uk
}

Fecha de recepción: 24 de febrero de 2015

Fecha de aprobación: 1 de julio de 2015

Sugerencia de citación: Villaveces, M. y Rodríguez P. (2015). El imaginario de la crisis: caricatura económica en Colombia en la época de la Gran Depresión.

tiempo\&economía, 2(1), 89-110 


\title{
Resumen
}

En el presente documento utilizamos las caricaturas económicas que aparecieron en el principal periódico colombiano (El Tiempo) entre 1928 y 1937, como una fuente primaria válida para el análisis de las tensiones que los fenómenos y situaciones económicas generaron en Colombia en una época tensa para la economía mundial. A través de la caricatura económica es posible ver la percepción de la opinión pública respecto a las políticas económicas y el temor e incertidumbre que éstas causaban en el común de la gente.

Palabras clave: historia económica, caricaturas, años treinta, Colombia.

Códigos JEL: N01, N16, N26, N46

\begin{abstract}
In this paper we use economic cartoons that were published in the leading Colombian newspaper -El Tiempo - between 1928 and 1937, as a valid primary source for analysis of the tensions and economic situations lived in Colombia during a tough worldwide economic period. Through economic cartoon it is possible to observe the perception of public opinion on economic policies and the fear and uncertainty that these were having on ordinary people.
\end{abstract}

Keywords: economic history, cartoons, 30s decade, Colombia.

JEL codes: N01, N16, N26, N46 


\section{Introducción}

La imagen ha acompañado a la humanidad en su historia como reflejo y expresión de sucesos, sentimientos, situaciones o imaginarios. La caricatura, como imagen, igualmente ha permitido la expresión de eventos, inconformidades, burlas, y reflejar momentos de la historia política, social y económica de las sociedades. La misma surge en la prensa escrita para acompañar las noticias y los editoriales con contenido satírico y, a la vez, crítico de los eventos diarios. En Colombia florece en el siglo XIX como parte de la ola creciente de nuevos periódicos de distintas tendencias políticas.

La definición básica de caricatura explica que se trata de una forma de generar humor, y significa "cargar la mano" o "exagerar los rasgos". En el sentido tradicional, es una forma de expresión (casi siempre gráfica) que distorsiona o acentúa los rasgos, y aunque no forzosamente se hace con el propósito de ridiculizar, lo más frecuente es que esté presente una intención crítica o satírica de un individuo, grupo o sociedad. Para Foxley, el dibujo soporta un concepto que se basa en la contradicción entre las imágenes y el texto (citado por Soto, 2003, p. 99).

En particular, la caricatura permite ver aspectos sobre las sociedades que usualmente no son observables a través de otras fuentes, y en su diversidad y conflictos se ve cómo se determinan y modifican las relaciones sociales. Todo gracias a la necesidad de utilizar los símbolos de una "mentalidad colectiva".

La historiografía y el análisis de caricaturas han puesto especial atención a las caricaturas editoriales con contenido político. Cabe señalar los siguientes ejes temáticos: representaciones de hechos e instituciones políticas, como la representación de la imagen de la Presidencia de EE. UU., tras el 11 de septiembre (Lamb, 2004); la construcción de imágenes nacionales a través de las relaciones internacionales, como la evolución de la imagen que percibe Occidente del islam (Michlemore, 2000), o la percepción de británicos y alemanes tras la Segunda Guerra Mundial (Moyle, 2004); la creación de la imagen nacional en oposición al otro, como en el caso de Argentina sobre la definición de los límites geográficos con Chile (Zusman y Hevilla, 2004); la realización de varios trabajos que incluyen las caricaturas como fuente primaria en la historia política, siendo los principales los de Colmenares (1984), González (1990) y Acevedo (2000a y 200b); otros, como Obregón (1990) y Escobar (1994), resaltan el papel de la caricatura y el caricaturista en la historia política y de la opinión pública. En América Latina en general podemos encontrar diversos trabajos, como los de Abreu (2001), Rivera Escobar (2005) y Dettleff y Olivera (2008), entre otros.

En general, los estudios se concentran en la capacidad de los dibujos para reflejar situaciones específicas de la vida política de un país, sus personajes, sus tensiones, los debates y la opinión que esto genera en la gente común. Se pueden mencionar los trabajos sobre guerra, conflictos de género, partidos políticos, relaciones internacionales, entre otros.

Sin embargo, ha sido pobre el interés de la historiografía por analizar temas económicos reflejados en las caricaturas. Encontramos los trabajos de Aurrecoechea (1993), Peart y Levy (2007) y Villaveces (2011). El primero se enfoca en la caricatura mexicana de principios de los años noventa en el marco de la globalización. Por su parte, Peart y Levy (2007) se enfocan en las caricaturas para entender cómo la opinión pública explica el significado de escasez y 
riqueza, fundamentales en el análisis económico. Por último, el trabajo de Villaveces (2011) hace un recorrido de más de un siglo de caricaturas económicas en Colombia para ilustrar los principales temas que suscitaron interés en la opinión pública, aun alejándose de las realidades económicas o de la interpretación de los hechos.

Partiendo de las afirmaciones hechas por Kemnitz (1973), Heitzmann (1974, 1988 y 1998), Fetsko (2001) y Thomas (2004), es legítimo aseverar que las caricaturas pueden utilizarse como una fuente primaria válida para investigación y estudios históricos. Al ser considerada una fuente primaria válida, creemos que es relevante utilizarla para el análisis de fenómenos y hechos económicos. No obstante, reconocemos que no es una fuente exacta y verídica en su totalidad. Como lo mencionó Colmenares (1984, ix), la caricatura es un reflejo que se sustenta en "el subentendido de la epidermis de los hechos", no es una reproducción fiel de los detalles de la historia.

En particular, consideramos que la caricatura con contenido económico -caricatura económica - puede ser utilizada como fuente para el análisis de la historia económica, en dos perspectivas. Por un lado, como una fuente que refleja particularmente una coyuntura económica específica en un momento puntual (una crisis inflacionaria, un incremento de impuestos, etcétera). Por otro lado, como una fuente que expresa problemáticas o asuntos económicos generales (el empleo, la pobreza, la función del economista, entre otros), que ilustran los temas que preocupan a la economía como disciplina y a los lectores afectados por dichos aspectos económicos. En este caso, no es necesaria la vinculación a un momento histórico. El tema, al ser genérico, permite un acercamiento a los asuntos que más interesan a la opinión pública. En este documento tomaremos la definición "caricatura económica" en sus dos sentidos. Sin embargo, como señala Villaveces (2011), la caricatura es un reflejo sesgado, y no necesariamente verídico, pero permite cuestionar y pensar los hechos que la acompañan.

Indudablemente, la historia económica de Colombia puede complementarse con un análisis de caricaturas económicas. En una revisión inicial, se encontró un número significativo de caricaturas económicas para el siglo XX que permitieron concluir que existe material importante para el análisis de caricaturas y economía. No obstante, es fundamental ser cuidadoso con el análisis a través de las caricaturas, pues éstas son un reflejo de hechos a partir de la visión y mirada de un autor que, seguramente, tiene un sesgo de opinión. Sin embargo, el valor histórico e historiográfico de las caricaturas económicas en Colombia invita a una lectura y un análisis diferentes de los hechos económicos.

Siguiendo a Acevedo (2000a), se debe rescatar la caricatura como fuente histórica de análisis, no obstante la carga ideológica y el sesgo que simbolizan los dibujantes. Más que una herramienta para establecer hechos puntuales, la caricatura permite dar una idea de la manera como se estaban interpretando y percibiendo los hechos en un momento específico. La caricatura permite acercarse al ambiente e imaginario de una época, permite rememorar y entender las particularidades de situaciones políticas, sociales o económicas. También permite acercarnos a los temas que fueron parte del debate diario y estaban en la mira de la opinión pública, más allá de lo que es considerado importante con la visión retrospectiva de la historia económica convencional. En esta medida, es una fuente histórica importante y singular. 
En este sentido, el presente documento busca identificar las problemáticas económicas salientes en la prensa escrita y a la luz de la opinión pública durante la época de la Gran Depresión. Es decir, partimos del hecho de que no todas las circunstancias económicas ex ante y ex post la Crisis del 29 fueron objeto de interés de los caricaturistas, puesto que éstos reflejan los problemas o las circunstancias más sensibles para la opinión pública. En este sentido, haremos un análisis de los temas tratados por los caricaturistas, con especial atención a las críticas y sátiras reflejadas en sus dibujos. Por otro lado, nos centraremos en los años 1928-1934 como el período de crisis. A pesar de que históricamente el punto de inflexión sea octubre de 1929 a la hora de hablar de la Gran Depresión, varios eventos anteriores a la fecha dejan ver que la crisis estaba comenzando en Colombia una año antes, en especial por el creciente déficit fiscal y el cierre del crédito externo.

El documento está dividido en cuatro partes. La primera, esta introducción. En la segunda se plantea la importancia para el país del período de finales de los años veinte y principios de los treinta. En la tercera parte se presentan los debates más evidentes en las caricaturas de opinión, y en la última se presentará la conclusión.

\section{El ocaso de los veinte, la crisis de los treinta}

La época que antecede la Crisis del 29 y los años posteriores ha sido un asunto ampliamente tratado por la historiografía económica colombiana. Autores como Bejarano (1985), Echavarría (1999), Palacios (2002), Ocampo (1984), Meisel (1990b), Sánchez et al. (2007), Rodríguez (1973), entre otros, han abordado los temas más sensibles de este período, como el despegue cafetero, la entrada masiva de capitales al país, el creciente endeudamiento externo, la ortodoxia cambiaria y las políticas y programas monetarios.

En general, a partir de la década de los veinte el país experimenta un cambio significativo en su desempeño económico. El gasto público, el café, la infraestructura, el nivel de crédito y la transición del desastre monetario de fines del siglo XIX hacia una nueva institucionalidad monetaria reflejan la dinámica que estaba experimentando la economía, aunada a una nueva dinámica política y social.

El flujo de recursos a la economía colombiana a partir de exportaciones, endeudamiento externo, ingreso de capital extranjero y recursos aduaneros por cuenta de las importaciones dio lugar a la "Danza de los Millones", época de auge económico que se vio reflejado en el crecimiento de las inversiones públicas, especialmente en infraestructura de transporte.

Adicional a esto, el país inició un proceso de institucionalización económica que incluyó la Misión Kemmerer, en 1923, dirigida por el estadounidense Edwin Walter Kemmerer y encargada de la reforma de las finanzas nacionales, y de la cual, como resultado, surgió la fundación del Banco de la República, la Contraloría General de la Nación, el Banco Agrícola Hipotecario y la Superintendencia Bancaria.

Sin embargo, el país alcanzó unos niveles de endeudamiento que excedían su capacidad y que ya habían sido advertidos en la Misión Kemmerer como riesgosos para la estabilidad económica. En 1926, Carlos Uribe Echeverry indicó que la emisión por parte del banco central 
era el origen de "la carestía de la vida" (citado por Meisel, 1990a, p. 271), que se hacía evidente en el incremento de los niveles de inflación. En 1928, frente a tal nivel de endeudamiento, ${ }^{1}$ el candidato presidencial Alfonso López Pumarejo señaló la situación económica del país como "Prosperidad al Debe", por los efectos en las finanzas públicas de un período de prosperidad económica.

Como se mencionó, la década de los veinte significó el crecimiento del endeudamiento externo, que a partir de 1926 crece vertiginosamente. El progresivo endeudamiento externo generó preocupaciones y tensiones partidistas. En 1928, Laureano Gómez hizo alusión al endeudamiento externo señalando que excedía la capacidad de pago del Estado, y peor aún, que no se estaban realizando inversiones productivas. En un discurso, señaló que los ingresos desaparecían, pero no las deudas, y que eso podría llevar a la bancarrota o a entregar los recursos naturales y la "independencia económica" (citado por Pécaut, 2001, p. 108).

Realmente, los síntomas de la crisis mundial de fines de los veinte comenzaron a sentirse en el país hacia fines de 1928, cuando se frenaron los flujos de préstamos externos como consecuencia del incremento de las tasas de interés en el mercado de Nueva York, que desvió el flujo de fondos hacia Wall Street. A esta situación externa se sumó la desconfianza generada por el nivel de endeudamiento contraído por los municipios y departamentos de Colombia, que alcanzó a representar el 55,2\% de la deuda externa del sector público. Este escenario fue visto por el Departamento de Comercio de Estados Unidos como una situación preocupante, que advirtió acerca de los peligros si continuaban los empréstitos a Colombia.

Los años treinta inician bajo la crisis mundial, sumada a cambios significativos en el ámbito nacional, tales como el fin de la hegemonía conservadora, la guerra contra Perú y varios ajustes y reformas económicos. En el plano político, el fin de la hegemonía conservadora abrió una ventana de esperanzas a las reformas que requería el Estado para salir de la etapa de postración en la que se encontraba. A esto se sumó la crisis, que hizo inminente la necesidad de enfrentar las difíciles situaciones que se cernían y que llevaron al recién elegido presidente de la República, Enrique Olaya Herrera, a contratar la Segunda Misión Kemmerer. Para el Presidente, la crisis se debía tanto a hechos externos - el precio del café- como a errores en el tema de los empréstitos. ${ }^{2}$

La Gran Depresión comenzó a sentirse en Colombia con la caída de los precios del café a fines de 1929; sin embargo, los efectos negativos fueron compensados con el incremento de la cantidad exportada de grano en el período entre 1929 y1933. En términos comparados, Colombia fue el país de América Latina donde la crisis fue más leve, con una caída del PIB relativamente menor y una rápida recuperación (Meisel, 1990a, p. 291).

Los caricaturistas no estuvieron al margen de estos cambios. De la pluma de Ricardo Rendón (1894-1931), Adolfo Samper (1900-1989) y Alberto Arango (1897-1941) y Basilio vemos cómo se expresan e interpretan los cambios económicos. La caricatura, en este contexto, cumple el papel de representar las tensiones frente a los cambios en la dinámica económica. Reconocemos que las caricaturas son subjetivas y pueden estar sesgadas por la interpretación de dibujantes; sin embargo, reconocemos también su valor como fuente primaria para el análisis de la historia

1 En total, 6,9\% del PIB y 5,5\%, debido a deuda externa, según Junguito y Rincón (2004, p. 38).

2 Carta del presidente Olaya Herrera a Edwin Kemmerer, citado en Meisel (1990b, p. 328). 
económica. Siguiendo esta perspectiva, las caricaturas económicas se utilizarán como vehículo para interpretar los eventos y tensiones de la economía en un período complejo, como fue la época de la crisis y tensión económica de los años treinta. Vale la pena resaltar que no todos los temas económicos son objeto de los caricaturistas, más bien se enfatiza en temas financieros como crítica al gobierno saliente, y en temas monetarios, por temor a los efectos en la moneda de una crisis mal manejada. Temas como el café, la industria, el comercio, los enclaves, entre otros, nos son visibles a la luz de los caricaturistas, siendo temas fundamentales para la historia económica de Colombia en el período de análisis.

\section{Las caricaturas en el contexto económico: dificultades financieras, endeudamiento y guerra}

Varios debates se dan en 1928. Por un lado, la tesis patriótica respecto de los empréstitos, igualmente afectada por el rechazo a los petroleros extranjeros; sobre los efectos de los empréstitos norteamericanos que llevarán a "lazos fatales", sometiendo al país a la influencia angloamericana. Se plantean la cuestión de la soberanía y el malestar que los empréstitos pueden generar sobre la independencia del país, más con los casos recientes de países como Nicaragua, que debió enfrentar una invasión de Estados Unidos. Esta tesis sugiere que, dado que no es posible prescindir de los créditos, es necesario buscar un equilibrio en la demanda de crédito a Estados Unidos y a Europa como manera de mitigar los "lazos fatales".

Otro debate estuvo asociado con el presupuesto y el tamaño que había alcanzado la deuda pública. Según la prensa, la deuda del gobierno había alcanzado 6,9 puntos del PIB. Según Esteban Jaramillo (ministro de Hacienda), la deuda tan sólo ascendía a 7,7\% del presupuesto nacional, y argumentaba que "toda nación necesita deuda para desarrollarse. La inflación, como expansión de la moneda, y el crédito bancario han servido para el desarrollo". Para el Ministro, el gran problema no era la deuda sino la tendencia inflacionaria que generaba, lo cual fue refutado por Félix Salazar (gerente del Banco de la República), quien argumentaba que la inflación que estaba experimentando el país era causada por el verano y sería pasajera. ${ }^{4}$

La caricatura 1 (de 1928) refleja una situación tensa respecto al excesivo gasto público, sumado a las dificultades de pago de intereses de los créditos adquiridos por la nación. Rendón utiliza la escena bíblica del festín de Baltasar (Libro de Daniel, cap. 5) para ilustrar lo que a su juicio estaba ocurriendo: el gobierno había profanado el presupuesto nacional (con las copas sagradas hurtadas del templo de Jerusalén), y la opinión pública se manifestaba indignada (la mano misteriosa que escribió en el palacio del príncipe babilonio Mane Thecel Phares, que es interpretado como el "fin próximo fatal"), anunciando la división y el colapso de la nación. De esta manera, Rendón anunciaba el fuerte impacto que tendría la crisis sobre la favorabilidad del Partido Conservador.

3 El Tiempo, 11 de enero de 1928.

4 El Tiempo, 4 de diciembre de 1928.

tiempo\&economía

No2 - I semestre de 2015

p. 95

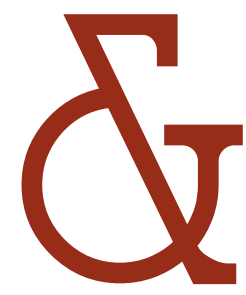




\section{Caricatura 1. El festín de Baltasar, Rendón}

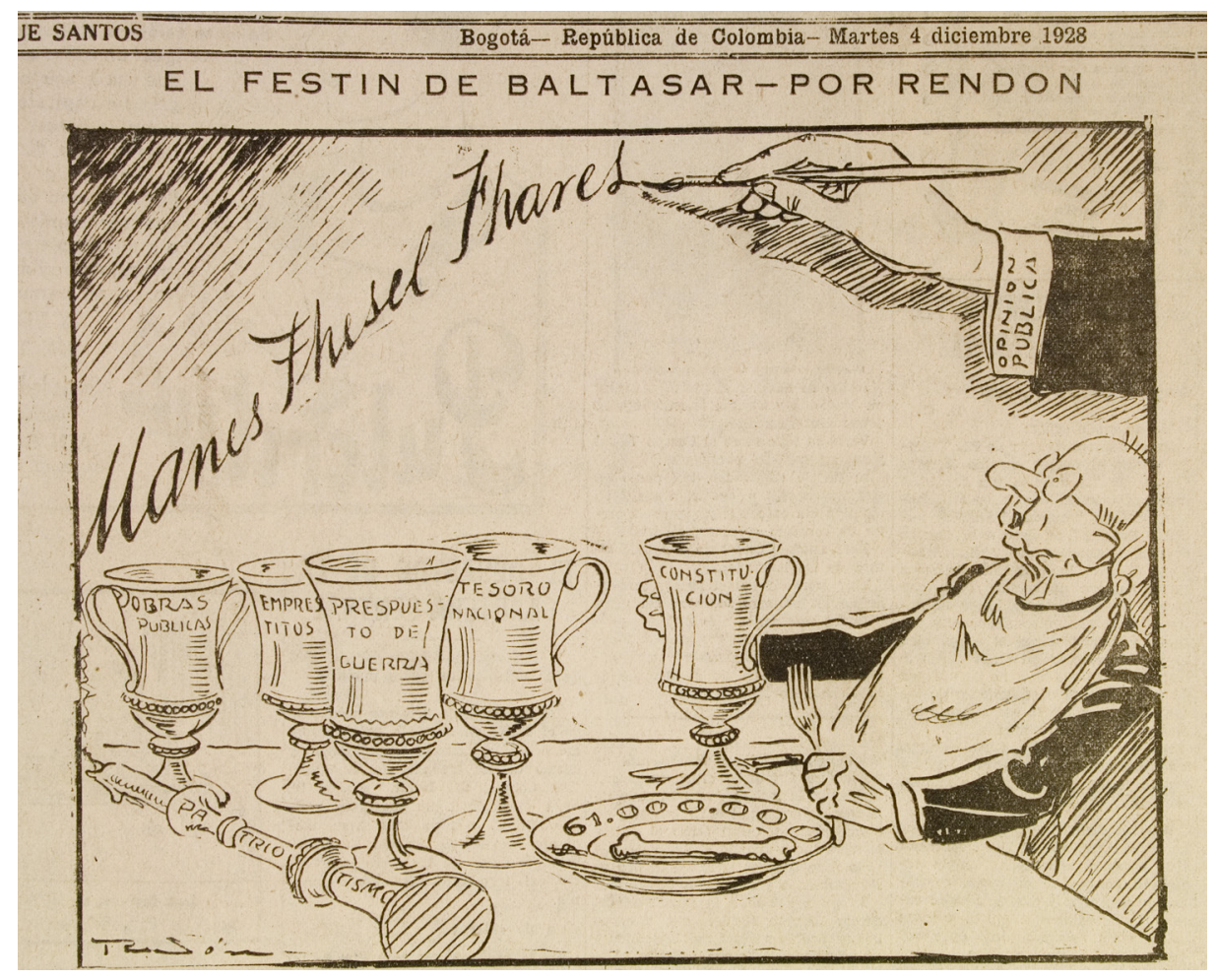

Fuente: El Tiempo, 4 de diciembre de 1928.

Varios analíticos y políticos señalaban las dificultades económicas que se avecinaban para el país, sin que el gobierno pareciera tomar medidas restrictivas en cuanto al gasto. En este año empieza una clara restricción al crédito externo, con el aumento de las tasas de interés de la Reserva Federal de Estados Unidos y la dificultad de colocar bonos oficiales de deuda pública en el mercado internacional, como intentaba hacerlo el recién creado Banco Agrícola Hipotecario (Junguito y Rincón, 2004, p. 39). En este contexto, el Congreso de la República emitió la Ley $5^{\mathrm{a}}$, cuyo objetivo fue restringir los empréstitos departamentales y municipales a aquellos que fueran de obras públicas y de utilidad pagadas fácilmente. No obstante, fue insuficiente para impedir la "huida" del crédito externo y las inversiones de los que dependía el país, especialmente para los ferrocarriles, lo cual generó caos y despidos a lo largo de 1929.

Sin embargo, el gobierno se mostraba optimista frente a la situación fiscal. El 26 de julio de 1928, Esteban Jaramillo se expresó en defensa de los empréstitos internos únicamente para las grandes obras de interés nacional, como fórmula para la crisis:

[...] ningún país ha podido realizar la estabilidad de sus presupuestos de gasto, pero la experiencia ha demostrado invariablemente que donde estos gastos crecen de manera desproporcionada a los ingresos efectivos, la economía nacional se siente seriamente amenazada. Vienen entonces los arbitrios fiscales más o menos peligrosos, los empréstitos para gastos ordinarios de la administración y, por último, la mayor de las calamidades, que es el papel moneda de curso forzoso. ${ }^{5}$

5 El Tiempo, 26 de junio de 1928. 
La situación de dudas sobre la capacidad de pago de la nación y de los departamentos y municipios estancó los préstamos y precipitó la caída de los precios de los bonos del tesoro emitidos por el gobierno colombiano, algunos meses antes de la crisis de la bolsa en $1929 .{ }^{6}$ A finales de 1928 desapareció el optimismo reinante que se reflejaba en la prensa; a partir de entonces, los titulares hicieron referencia al estancamiento general de los negocios, la caída de las cotizaciones bursátiles y el exceso de gasto público. La prensa liberal culpaba al gobierno conservador de la crisis de obras públicas y de la política financiera del país. Lo acusaban de "derroche desenfrenado de los empréstitos". Al iniciar 1929, el editorial de El Tiempo del 5 de enero señalaba que era conveniente "atenuar" los compromisos financieros con el exterior, al menos de forma transitoria. En la misma fecha, un comentario del Contralor de la República afirmaba que eran tres las causas de la crisis económica que estaba viviendo el país: 1. El aumento del circulante por cuenta de los empréstitos externos importados y por la amplitud del crédito. 2. La competencia en obras públicas, que presiona el salario al alza y desvía los recursos de los préstamos al pago de mano de obra. 3. La falta de acción oficial para el fomento en la protección a la agricultura.

La tensa situación de los empréstitos en Colombia es dibujada por Rendón, quien refleja la opinión de la crítica de ese entonces: la inyección de empréstitos provenientes principalmente de Estados Unidos, que hacen referencia a la política de la "prosperidad al debe", habían "inflado" la economía colombiana; luego de esta situación, la solución es una dolorosa crisis para Colombia, reflejada en la extracción no sólo de una muela, sino también de la quijada (ver la caricatura 2). Todo esto reflejaba la difícil situación que estaba viviendo el país desde 1928, prácticamente un año antes del crash de la bolsa de Nueva York.

La crisis de 1929 tuvo un impacto en la economía colombiana. A la depresión mundial se sumó la crisis del café, que afectó la economía del país. Frente a la caída de las exportaciones y el cierre del crédito externo, el gobierno se vio enfrentado a un derrumbe de sus ingresos. Ante esta situación, el gobierno reaccionó con una política ortodoxa de reducción de gastos. El gasto corriente se redujo en un 60\% entre 1928 y 1931 (Avella, 2003). No obstante, esta reducción no afectó el servicio de deuda pública, que siguió pagándose sin interrupción. Las caricaturas de Rendón de 1929 muestran a Colombia de rodillas suplicando por los créditos que salían al trote, con la complicidad del presidente Abadía (ver la caricatura 3).

En este mismo período hubo esfuerzos ilimitados por iniciar proyectos en obras públicas, que no siempre fueron exitosos o terminados. Un ejemplo de esto fue el intento de la conexión ferroviaria de Barranquilla hasta Puerto Colombia, fundamental para la dinámica comercial del café. El Puerto, a tan sólo 15 kilómetros del puerto fluvial del río Magdalena, era propicio para la interconexión con la economía mundial. No sólo permitió la salida sino que también fue la ruta de las importaciones al interior del país. No obstante, a principios del siglo XX, el desarrollo del puerto de Buenaventura significó una reducción importante del tráfico a través de Puerto Colombia. Esto parece ser una causa suficiente para que los empresarios de Barranquilla tomaran la decisión de iniciar la construcción de un puerto en la ciudad, a escasos

6 Se emitieron bonos por $\$ 35.000 .000$, con un interés del $6 \%$. Estos bonos se colocaron en el mercado de Nueva York al $95 \%$, con un interés para los tenedores del 6,33\%. Había optimismo y expectativas con respecto a la posibilidad de mejorar el crédito público gracias a este empréstito. Se menciona "la absoluta necesidad en que estamos en conservar intacto nuestro crédito en los mercados extranjeros" (EI Tiempo, 24 de julio de 1928). 
Caricatura 2. La crisis, Rendón

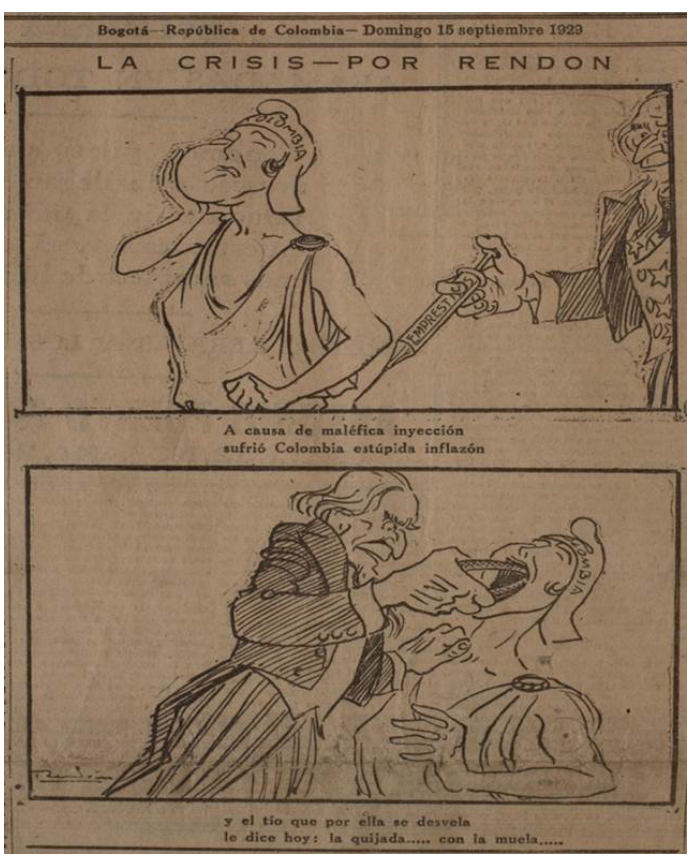

Fuente: El Tiempo, 15 de septiembre de 1929.

Caricatura 3 . La figura del crédito, Rendón

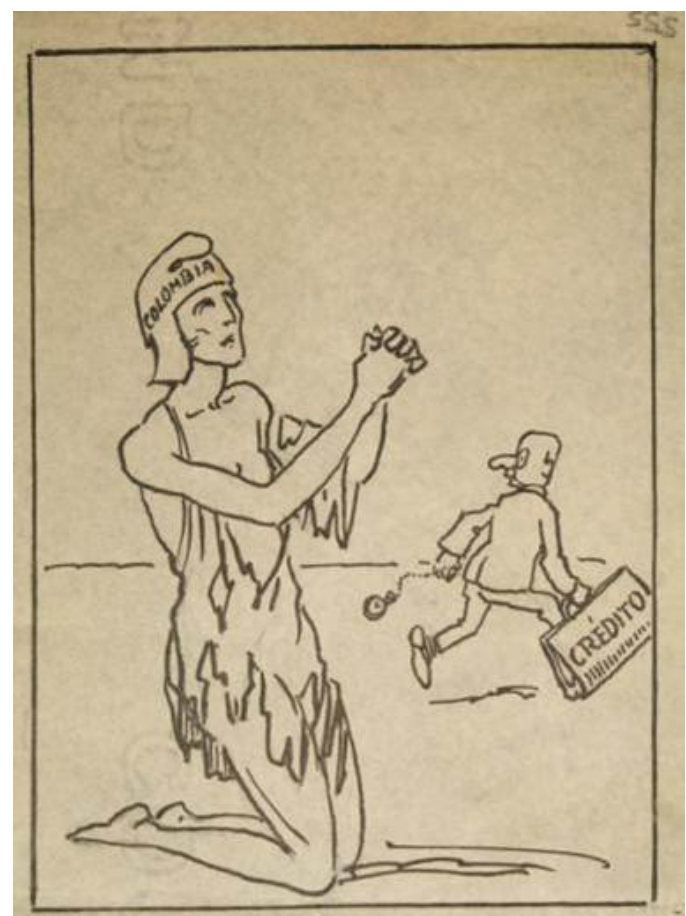

Fuente: El Tiempo, 15 de enero de 1929.

kilómetros de la desembocadura del río Magdalena. Este proyecto exigía una construcción de inmensa magnitud para lograr la entrada de los barcos al puerto. La obra de Bocas de Ceniza comenzó en 1925, cuando se firmó el contrato del gobierno nacional con la empresa Ulen. 
Rendón fue un fuerte crítico del proyecto de Bocas de Ceniza, y como resultado, una serie de caricaturas se inspiró en el tema. Concentramos la atención en la caricatura 4, que comenta la suspensión de los trabajos del megaproyecto, reflejo de la crisis nacional y una razón adicional de alarma para la ciudad de Barranquilla, por el importante número de trabajadores que fueron despedidos. ' La caricatura muestra las "Bocas de Ceniza" como niños hambrientos a raíz del proyecto. Un brazo con la etiqueta de "chichimoco" jala de la mesa los alimentos para estas "bocas", lo cual es un reflejo de la decisión del ministro de Obras Públicas, Arturo Hernández —Chichimoco-, cuando frena los recursos del gobierno para el megaproyecto. Rendón realiza un ataque a los grupos que defienden la construcción del proyecto, reflejo de la fuerte arremetida que recibió el proyecto por parte de la oposición liberal.

\section{Caricatura 4 . Las Bocas de Ceniza, Rendón}

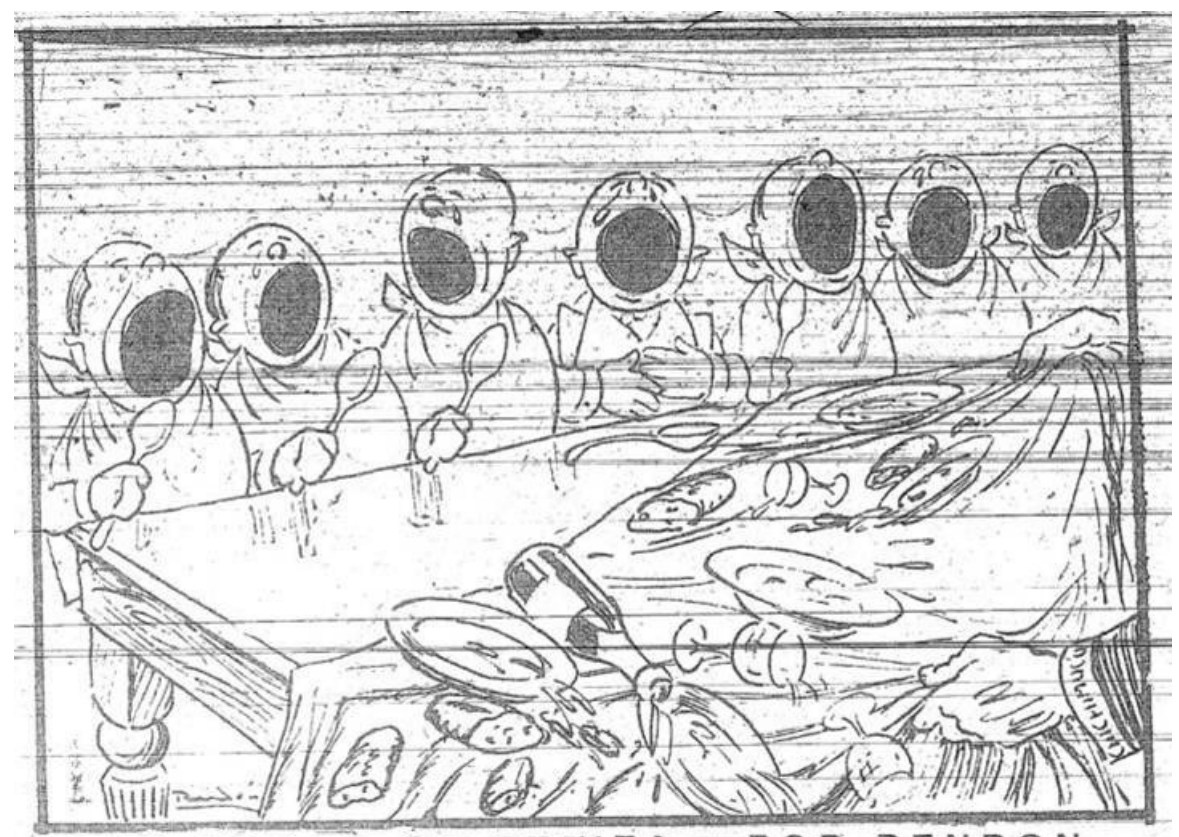

LAS BOCAS DE CENIZA—POR RENDON

Fuente: El Tiempo, 22 de enero de 1929.

La compañía Ulen detuvo los trabajos en 1929, y el gobierno estaba dispuesto a cambiar la concesión de dueño pero se enfrentó a la severa crisis financiera. Rendón nos muestra que la ilusión del gobierno estaba puesta en conseguir un empréstito para sacar adelante el proyecto, pero que esto no era más que un sueño en la crisis. El proyecto sería respaldado por el presidente Olaya y entregado en la administración de López Pumarejo, en 1936.

A finales de 1929, la sensación de crisis es inminente. Las editoriales de El Tiempo reflejaban el pesimismo de esos días. Se resaltaron la pérdida de los empréstitos y la baja en el precio del café como señales de la pérdida de "bienestar y holgura" que se veía venir. ${ }^{8}$ Días después, el mismo diario señala que "la crisis de 1929 será mucho más grave de lo que se cree".

7 Se pasó de 800 obreros en 1928 a menos de 50 trabajadores, según Viloria de la Hoz (2000, p. 17).

8 El Tiempo. Editorial, 1 de noviembre de 1929.

tiempo\&economía

N² - I semestre de 2015

p. 99 
Como vimos, la coyuntura fue desfavorable para la hegemonía conservadora, que llevaba varios años en el gobierno. La magnitud de la crisis económica se sumó a tensiones sociales y políticas que llevaron a la elección del presidente liberal Enrique Olaya Herrera, dando inicio a un período de gobierno liberal.

Lo que comenzó siendo un problema del gobierno por el cierre de los empréstitos internacionales, se tradujo en una suma de problemas para la población. En términos agregados, la oferta monetaria comenzó a caer, con los efectos en la tasa de inflación (negativa) y las dificultades para obtener circulante. De la pluma de Rendón, una caricatura de 1930 refleja la dificultad del pueblo para conseguir recursos: conseguir cinco pesos no es un problema, son cinco problemas (ver la caricatura 5).

Caricatura 5. La crisis, Rendón

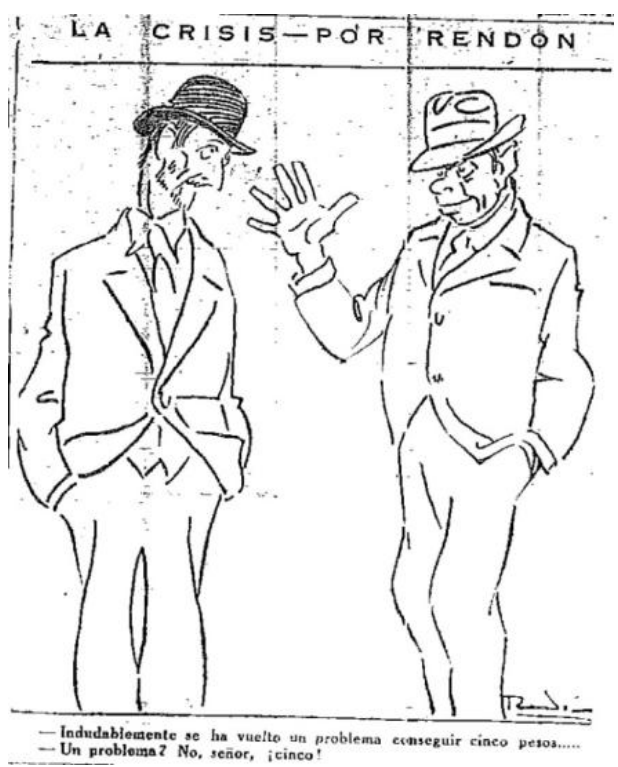

Fuente: El Tiempo, 2 de julio de 1930.

En este escenario de crisis económica y cambios políticos, el gobierno del recién posesionado presidente Olaya Herrera toma la decisión de volver a contratar la Misión del doctor Kemmerer, ${ }^{9}$ para dar pautas financieras y económicas frente a la situación que vivía el país. Producto de esta Misión, se entregaron varios proyectos de ley que fueron parcialmente implementados en los años siguientes, casi todos relacionados con reorganización de las rentas, las aduanas, el presupuesto y reformas tributarias.

A un mes de su llegada al país, el doctor Kemmerer dio un espaldarazo a la política monetaria nacional, al afirmar que ninguno de los bancos colombianos se quebró al mantener el patrón oro. A su vez, señaló que las recomendaciones hechas por la Misión que encabezaba se

9 La primera Misión del economista Kemmerer fue en 1923, cuya principal recomendación fue la organización de la banca central y una institucionalidad alrededor de la fundación del Banco de la República. Esta misión llegó al país luego de dos décadas de caos monetario heredado de la excesiva emisión del período de la Guerra de los Mil Días. En la población, la Misión generó un clima de tranquilidad frente al manejo desbordado. 
enfocaban en cinco categorías de las finanzas: la moneda y bancos, el presupuesto y contabilidad, los impuestos, la administración de aduanas y el crédito público. ${ }^{10}$

Junto a las propuestas de la segunda Misión Kemmerer, dos decisiones tuvieron impacto en las finanzas públicas y la moneda. Por un lado, el abandono de la ortodoxia monetaria, es decir, el abandono de patrón oro con libre cambio, en 1931. Por otro lado, a partir de 1931 se decretó una moratoria parcial en el servicio de deuda externa; sin embargo, el drenaje de recursos para el servicio de deuda era excesivo, lo que llevó a la moratoria total en 1934, posterior al conflicto con Perú.

En este contexto, uno de los objetivos principales del gobierno era consolidar su imagen frente a los inversionistas externos, en especial, Estados Unidos, razón por la cual el presidente Olaya Herrera viajó a Estados Unidos. A finales de 1930, se manifestaba que con el nuevo gobierno liberal, los banqueros norteamericanos habían recobrado la confianza. Pero la llegada de 1931 y la compleja situación de los departamentos y municipios del país llevan a la "reconquista de la confianza externa". Rendón enfatiza este concepto en una caricatura, donde muestra al presidente Olaya Herrera siguiendo la "estrella polar", con motivo de su viaje al país norteamericano, haciendo alusión al presidente Marco Fidel Suárez, que utilizaba el término, La Doctrina de la Estrella Polar, para referirse a su política exterior, que colocaba a Estados Unidos como el principal socio político y económico de Colombia (ver la caricatura 6).

Caricatura 6. El viaje del presidente, Rendón

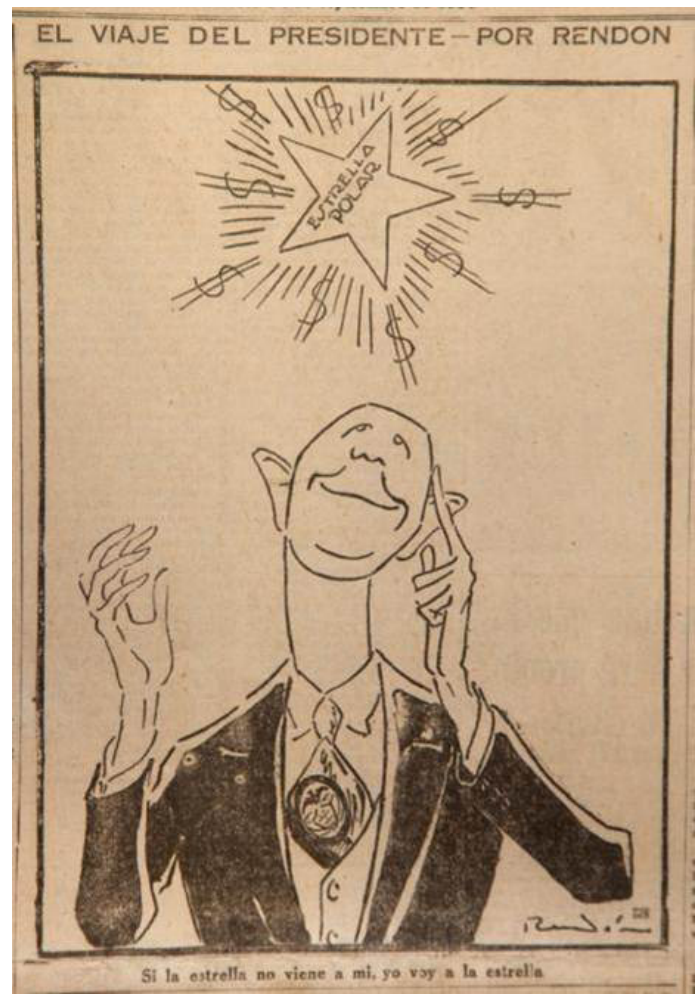

Fuente: El Tiempo, 1 de septiembre de 1931.

10 El Tiempo, 28 de septiembre de 1930. 
Caricatura 7. En pos de oro, Rendón. (En los papeles están escritos los diferentes ministerios)

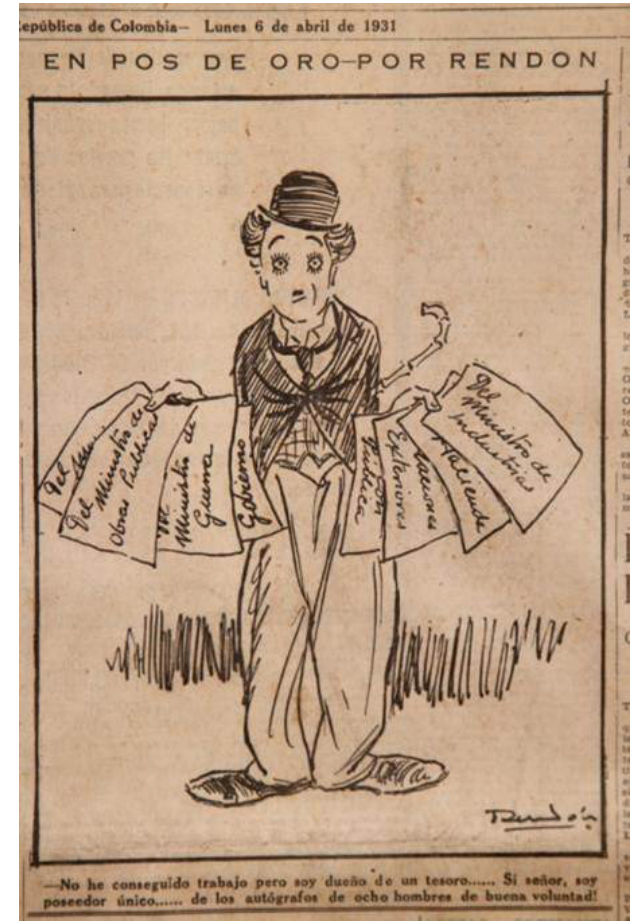

Fuente: El Tiempo, 6 de abril de 1931.

Luego de ceñirse con juicio a las reglas de la ortodoxia del patrón oro, las autoridades monetarias tomaron la decisión de abandonar la convertibilidad del peso y el control de cambios, en 1931. El tema de la convertibilidad tuvo una importancia y sensibilidad tales que la frase "pesos oro" sólo fue retirada del papel moneda en Colombia en la última década del siglo XX. El gobierno siguió la ortodoxia siempre hasta el último minuto, y en tal minuto creó una medida "temporal" (Avella, 2003, p. 5). El 24 de septiembre de 1931, las reservas de oro llegaron a extenuarse, y el sistema financiero interno estuvo al borde del colapso: el fin de la convertibilidad en Inglaterra llevó al pánico mundial, y en Colombia los clientes exigían oro a cambio de su papel moneda (Henderson, 2006, p. 354).

Las medidas del Banco de la República fueron anunciadas por el ministro Jaramillo, e incluían eliminar la convertibilidad de los billetes, abolir el libre comercio de oro, y su control directo por parte del emisor, y un esquema de control de cambios administrado por el banco central (Gaviria-Cadavid, 2003). La situación fue ampliamente caricaturizada; una caricatura de Rendón (caricatura 7) se refiere al tema utilizando un ícono cinematográfico de la época, Charles Chaplin, en su famoso rol del vagabundo, quien se encuentra desempleado pero cuenta con la buena voluntad del gobierno, representada en bonos firmados por cada ministerio. El mensaje es claro y directo: Rendón, a pesar de dibujar desde la prensa liberal, critica abiertamente la emisión de deuda sin respaldo y considera una burla el tema del abandono de la convertibilidad.

En 1932, luego de experimentar la fase más compleja de la crisis, el país entra por la vía de la recuperación económica presentando un crecimiento del PIB del 6,6\%, tal como se aprecia en el cuadro 1. La pronta recuperación de la economía nacional es representada por Samper, 
en 1932 (ver la caricatura 8), como una mujer hermosa con un brazalete que señala las mejoras en las reservas de oro, algo triste para la oposición conservadora. Basilio hace algo similar en el mismo año (ver la caricatura 9) representando al presidente Olaya guiando al pueblo sobre el difícil paso que representa la crisis, y que es aún más difícil por el peso que, a juicio del caricaturista, representan las administraciones anteriores. El presidente Olaya solicita serenidad en el difícil momento, reflejando su posición política, que de por sí es evidente al tratarse de un medio liberal.

Caricatura 8. Una ligera mejoría, Samper

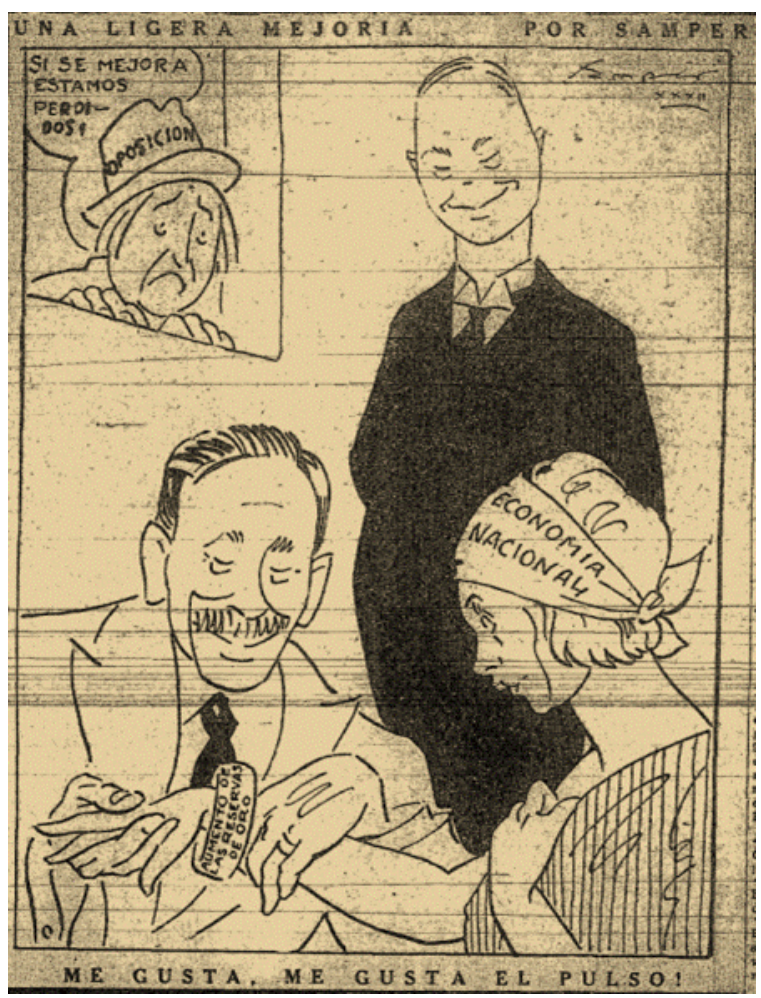

Fuente: El Tiempo, 8 de junio de 1932.

El período de mejoría fue descrito en la circular del Banco de la República del 7 de junio de 1932, donde se señala que por primera vez en tres años se observa una mejoría en la economía del país, gracias a la reserva sostenida de reservas de oro del Banco de la República, que pasó de 12 millones en marzo a 16 millones a finales de mayo, además del pago de 4 millones de crédito en el exterior y de contratos de cambio. Igualmente, se menciona que no sólo la deuda pública se ha ido cubriendo, sino que también se ha presentado una reducción del nivel de deuda externa de los bancos privados. Los esfuerzos del gobierno llevan a decir que la "balanza de pagos está trocando de adversa en favorable al país gracias a las medidas tomadas por el gobierno y a la actitud de orden y economía asumida por la nación".11

11 El Tiempo, 7 de junio de 1932. 
Caricatura 9. El mal paso, Basilio

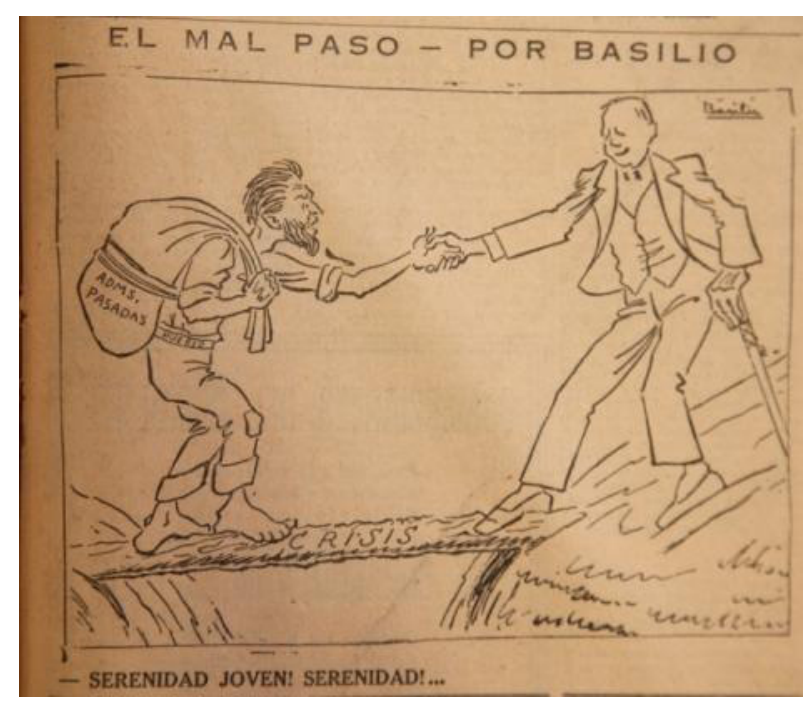

Fuente: El Tiempo, 28 de enero de 1932.

El período de análisis representó para Colombia un momento crucial en cuanto a su transformación social, política y económica. Durante tal década se da un cambio en el partido de gobierno que había permanecido en el poder desde hacía varias décadas; empieza con la Gran Depresión pero posteriormente incluye un ciclo expansivo de la economía; durante el mismo se dan grandes cambios en cuanto a política monetaria, cambiaria y fiscal. Además, la estructura de la sociedad y sus relaciones se transforman, junto a la estructura productiva. Todo lo anterior hace de esta década un período esencial para analizar la relación entre caricatura económica e historia económica. ¿Es posible que durante este período de crecientes roces políticos la caricatura económica sea parte principal de los editoriales? Hemos encontrado que sí, aunque prevalece la caricatura económica de coyuntura, altamente relacionada con la lucha política del momento; también podemos encontrar caricaturas genéricas, que son válidas sin importar la referencia histórica.

\section{Percepción del pueblo frente a las circunstancias económicas}

Son dos los temas que afectan directa e inmediatamente al pueblo, a las "personas de a pie": los precios y el desempleo. Si bien temas como la crisis, el déficit fiscal, la política cambiaria, y similares, afectan a toda la población, son los incrementos en el nivel de precios (por cualquier causa) o en el desempleo los temas que tienen un impacto casi inmediato en la población, y que se ven reflejados en la prensa, que recoge esa opinión pública. Evidencia de esto es el caso de las caricaturas relacionadas con estos temas. 
Estas caricaturas tienden a pertenecer más a la categoría genérica que a la coyuntural: una caricatura de 1934 sobre la inflación podría ser vista por un ciudadano a finales de 2007 o principios de 2008, y éste se sentiría perfectamente identificado. Es el caso de la caricatura del maestro Samper titulada La inflación (1934), donde unas vacas persiguen a unos empleados, y uno de ellos afirma que llegó la época de las vacas gordas (ver la caricatura 10).

\section{Caricatura 10. La inflación, Samper}

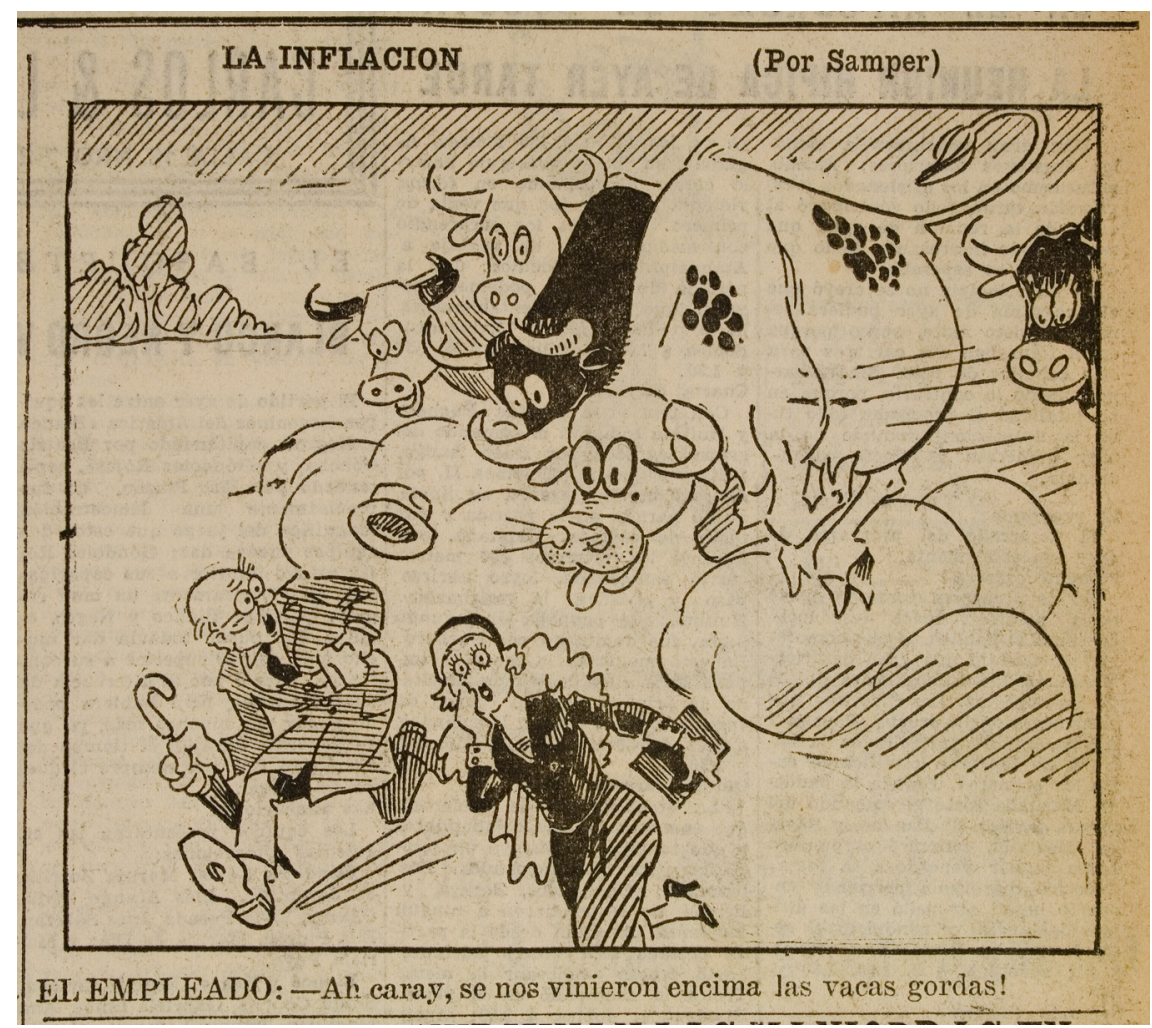

Fuente: El Tiempo, 23 de abril de 1934.

A pesar de lo anterior, en los años treinta encontramos un reflejo interesante de la política monetaria y cambiaria que afectaba directamente a la opinión pública, si bien el efecto sobre el ciudadano "de a pie" no era directo. Como vimos, el caso de la convertibilidad fue retratado en varias caricaturas, y esto iba ligado al temor que surgió tras la inflación de principios de siglo. Mediante las caricaturas, encontramos algo adicional: la oposición común y generalizada a interrumpir la convertibilidad.

Colombia adoptó el patrón oro, en aras de reconstruir el sistema monetario después de la Guerra de los Mil Días y los grandes excesos en la emisión. Sólo hasta la creación del Banco de la República se definiría un patrón único de convertibilidad en función del oro, un respaldo a la riqueza. La convicción sobre la necesidad del patrón oro no era puesta en duda, y cualquier intento por cambiar la situación generaría gran rechazo. 
Las caricaturas de Rendón, Samper y Arango dejan ver una situación inusual: las caricaturas van en contra de las políticas de devaluación, de forma sistemática, a pesar de encontrarse en un medio informativo oficial y ante una creciente polarización política. En general, la prensa escrita era un arma política de un partido político, y las caricaturas no eran la excepción. Según Acevedo (2000b), las caricaturas hacen parte del enfrentamiento simbólico entre las partes. No obstante, el tema de la convertibilidad no era parte de este esquema. Sus caricaturas consideraban que la solución "mágica" de la devaluación no podía traer nada bueno para el país. Vemos cómo Arango mantiene su posición en 1937, a pesar de la dinámica de la economía previa a la Segunda Guerra Mundial. En la caricatura 11, Arango enfatiza su posición respecto al significado de una devaluación, "quedar más pobres pero con más plata"; no obstante, el dibujante pone tal explicación en boca de una personalidad, el exministro Esteban Jaramillo, reflejando una posición política respecto al debate de una posible devaluación ante una caída en los precios del café. La imagen puede ser leída entonces de una forma general y una forma coyuntural.

\section{Caricatura 11. En el clavo, Arango}

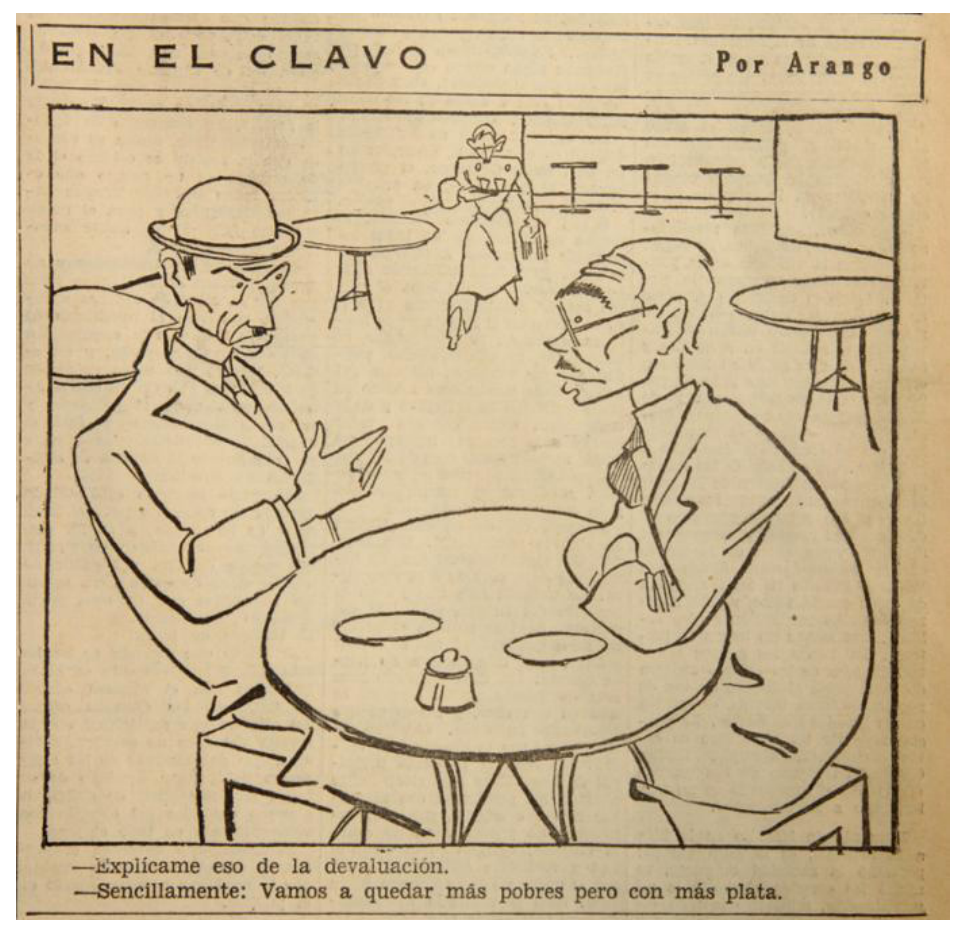

Fuente: El Tiempo, 10 de septiembre de 1937.

\section{A manera de conclusión}

Tal como se mencionó al inicio, la época que antecede la Crisis del 29 y los años posteriores ha sido un asunto ampliamente tratado por la historiografía económica colombiana. Sin embargo, hasta ahora no se ha utilizado la caricatura como una fuente primaria para pensar los eventos de la historia económica. 
La tensión de la época no fue ajena a la opinión pública, y así lo dejaron plasmado los caricaturistas en sus dibujos, que, con sátira y sarcasmo, lograron dejar evidencia de la tensión que estaban atravesando la economía y el país, siendo así una fuente válida y viable para el análisis de la historia económica. En una época tan compleja, la opinión pública no quedó rezagada en su interpretación. Se encuentran caricaturas con la habilidad de exponer y expresar decisiones fundamentales. En este caso, se recogieron las caricaturas que expresan temas como la deuda, la guerra contra Perú y la política cambiaria.

La sátira y burla se sienten en la mayoría de las caricaturas, como es de esperarse. En particular, encontramos un interés, que podría llamarse genuino, de los caricaturistas por temas económicos. Si bien no se pretende que reflejen o expliquen el problema económico de manera profunda, si deja ver un interés por lo que pueden ser las consecuencias sociales y políticas de las decisiones económicas. Rendón, Samper Arango y Basilio muestran con ironía la tensa situación en Colombia de las finanzas públicas y la moneda. El juicio de Rendón es brutal: una Colombia harapienta suplica por fondos de crédito externo. Igualmente, muestra la dificultad de entender la ley de conversión que se implementó en 1928. De las plumas de Arango y Samper se percibe una interpretación pesimista de la política cambiaria de principios de los años treinta.

Hemos visto cómo, a pesar de seguir a caricaturistas relativamente homogéneos en su ideología política, en el caso de los editorialistas de El Tiempo, el diario liberal por excelencia, sus posiciones frente a diferentes temas de índole económica no son tan marcadas como en aquellos puramente políticos. Es decir, los caricaturistas, al reflejar las situaciones económicas, logran separarse en parte del sesgo ideológico y hacer una descripción o caracterización más objetiva - dados sus conceptos- de la problemática que interpretan. En las caricaturas, en este caso, vemos que algunas políticas económicas eran impopulares, sin importar el partido político en el gobierno. Rendón atacó fuertemente a los ministros conservadores, pero también atacó al presidente Olaya Herrera — presidente liberal a quien en varias caricaturas había retratado como una especie de salvador de la patria - con el tema del dinero fiduciario, y Samper y Arango se mostraron inflexibles con las devaluaciones y los ministros de Hacienda, a pesar de estar en el diario que favorecía al gobierno de ese momento.

\section{Referencias}

Abreu, S. (2001). Periodismo iconográfico (X). Clasificaciones sobre la caricatura (y 2). Revista Latina de Comunicación Social 45. Recuperado de: http://www.ull.es/publicaciones/latina/2001/latina45diciembre/4506abreu.htm

Acevedo, D. (2000a). ¿Es la caricatura editorial una fuente para la investigación de la historia política? XI Congreso de Historia de Colombia, Bogotá.

Acevedo, D. (2000b). La caricatura y la Violencia liberal-conservadora. Revista Credencial, 125. Disponible en: http://admin.banrepcultural.org/blaavirtual/revistas/credencial/mayo2000/ 125caricatura.htm 
Aurrecoechea, J. M. (1993). La eterna historia del gordo y el flaco. Política y Cultura, no 3 invierno: pp. 233-262.

Avella, M. (2003). Antecedentes históricos de la deuda colombiana. El papel amortiguador de la deuda pública interna durante la Gran Depresión, 1929-1934. Borradores de Economía Banco de la República, 270.

Bejarano, J. A. (1985). Industrialización y política económica. En M. Arrubla (ed.). Colombia Hoy. Bogotá: Siglo XXI.

Colmenares, G. (1984). Ricardo Rendón. Una fuente para la historia de la opinión pública. Bogotá: Fondo Cultural Cafetero.

Demetriou, O. (2004). The Turkish oedipus: National self and stereotype in the work of a 1960s Greek cartoonist. History and Anthropology, 15 (1), pp. 1-36.

Dettleff, J. A. y Olivera, L. (2008). Caricatura, comunicación política y candidatos: Perú 2006. Miedos, reacciones y estrategias frente al "outsider". IX Congreso Latinoamericano de Investigadores de la Comunicación. México.

Echavarría, J. J. (1999). Crisis e industrialización. Lecciones de los treinta. Bogotá: Tercer Mundo, Banco de la República y Fedesarrollo.

Escobar, M. (1994). Ricardo Rendón: el humor hecho sátira. Centenario del nacimiento del mejor caricaturista colombiano del siglo XX. Revista Credencial Historia, 53.

Fetsko, W. (2001). Using and analyzing political cartoons. Education outreach, The Colonial Williamsburg Foundation. Recuperado de:

http://ali.apple.com/ali_media/Users/1000323/files/others/Political_Cartoons.pdf

Gaviria-Cadavid, F. (2003). Moneda, banca y teoría monetaria. Bogotá: Fundación Universidad del Bogotá Jorge Tadeo Lozano.

González, B. (1990). Tercera dimensión de la historia. La caricatura política en Colombia. En 160 años, crítica y humor: otra manera de juzgar los hechos. Revista Credencial Historia, 10.

GRECO (2002). El crecimiento económico colombiano en el siglo XX. Bogotá: Banco de la República.

Heitzmann, W. R. (1974). The political cartoon and the social science teacher. Social Studies, 65 (2), pp. 82-83.

Heitzmann, W. R. (1988). Political cartoon interpretation. Social Studies, 79 (5), pp. 212-213.

Heitzmann, W. R. (1998). The power of political cartoons in teaching history. Occasional Paper. National Council for History Education.

Henderson, J. D. (2006). La modernización en Colombia: los años de Laureano Gómez, 1889-1965 (M. Holguín, trad.). Medellín: Editorial Universidad de Antioquia - Facultad de Ciencias Económicas, Universidad Nacional Sede Medellín.

Junguito, R. y Rincón, H. (2004). La política fiscal en el siglo XX en Colombia. Borradores de Economía, 318. 
Kemnitz, T. (1973). The cartoon as a historical source. Journal of Interdisciplinary History, 'The Historian and the Arts', 4 (1), pp. 81-93.

Lamb, C. (2004). Drawn to extremes: The use and abuse of editorial cartoons. New York: Columbia University Press.

Meisel, A. (1990a). La organización del Banco de la República y su papel como gestor de la política monetaria durante los primeros años, 1923-1934. En El Banco de la República. Antecedentes, evolución y estructura. Bogotá: Banco de la República.

Meisel, A. (1990b). Los intentos por mantener el patrón oro. En El Banco de la República. Antecedentes, evolución y estructura. Bogotá: Banco de la República.

Moyle, L. (2004). Drawing conclusions: An imagological survey of Britain and the British... in German and British cartoons and caricatures, 1945-2000. Ph.D. Tesis, Universität Osnabrück.

Obregón, E. (1990). Ricardo Rendón. Retratista y caricaturista impecable. Revista Credencial Historia, 10.

Ocampo, J.A. (1984). Crisis mundial y cambio estructural (1929-1945). En J. A. Ocampo (comp.). Historia económica de Colombia. Bogotá: Tercer Mundo y Fedesarrollo.

Palacios, M. (2002). El café en Colombia 1850-1970. Una historia social y política. Bogotá: Planeta.

Peart, S. J. y Levy, D. M. (2007). Economics in cartoons. Chicago: Allied Social Sciences Association.

Pécaut, D. (2001). Guerra contra la sociedad. Bogotá: Espasa Hoy.

Rivera, R. (2005). Caricatura en el Perú, el período clásico (1904-1931). Lima: Biblioteca Nacional del Perú, Fondo Editorial.

Rodríguez, O. (1973). Efectos de la Gran Depresión sobre la industria colombiana. Bogotá: El Tigre de Papel.

Sánchez, F., Fernández, A y Armenta, A. (2007). Historia monetaria de Colombia en el siglo XX: grandes tendencias y episodios relevantes. En J. Robinson y M. Urrutia (eds.). Economía colombiana del siglo XX. Un análisis cuantitativo. Bogotá: Fondo de Cultura Económica y Banco de la República.

Soto, A. (2003). Caricatura y agitación política en Chile durante la Unidad Popular, 1970-1973. Revista de Historia de Chile y América, 2 (2), pp. 97-135.

Thomas, S. J. (2004). Teaching America's GAPE (or any other period) with political cartoons: A systematic approach to primary source analysis. The History Teacher, 37 (4), pp. 425-446.

Torres, G. (1945). Historia de la moneda en Colombia. Bogotá: Imprenta del Banco de la República.

Tovar, H. (1984). La intervención económica del Estado en Colombia 1914-1936. Bogotá: Biblioteca Banco Popular, Textos Universitarios.

Villaveces, J. (2011). Caricatura económica en Colombia 1880-2008. Bogotá: Centro Editorial Universidad del Rosario. 
Viloria de la hoz, J. (2000). Banco de la República en Barranquilla, 1923-1951. Cuadernos de Historia Económica y Empresarial, no 6. Centro de Investigaciones Económicas del Caribe Colombiano.

Zusman, P. y Hevilla, C. (2004). Las caricaturas periodísticas de finales de siglo XIX en la construcción de las fronteras del estado nación argentino. Revista Litorales, 4 (5). 